\title{
Direct Printing of a Multi-Layer Sensor on Pet Substrate for $\mathrm{CO}_{2}$ Detection
}

\author{
Bruno Andò ${ }^{1, *}$, Salvatore Baglio ${ }^{1}$, Giovanna Di Pasquale ${ }^{2}$, Antonio Pollicino ${ }^{2}$, \\ Salvatore Graziani ${ }^{1}$, Chiara Gugliuzzo ${ }^{2}$, Cristian Lombardo ${ }^{1}$ and Vicenzo Marletta ${ }^{1}$ (D) \\ 1 DIEEI University of Catania, v.le A. Doria 6, 95127 Catania, Italy; salvatore.baglio@unict.it (S.B.); \\ salvatore.graziani@dieei.unict.it (S.G.); cristian.lombardo@gmail.com (C.L.); \\ vincenzo.marletta@dieei.unict.it (V.M.) \\ 2 DII University of Catania, v.le A. Doria 6, 95127 Catania, Italy; giovanna.dipasquale@dii.unict.it (G.D.P.); \\ antonino.pollicino@dii.unict.it (A.P.); gugliuzzochiara@hotmail.it (C.G.) \\ * Correspondence: bruno.ando@unict.it; Tel.: +39-095-738-2601
}

Received: 20 December 2018; Accepted: 2 February 2019; Published: 12 February 2019

\begin{abstract}
The use of inexpensive gas sensors is a real need for many applications requiring the use of disposable sensors. This work deals with the realization and characterization of a low cost $\mathrm{CO}_{2}$ sensor realized by rapid prototyping techniques. In particular, the sensor consists of a set of InterDigiTed electrodes, over which a double sensing layer made of PEDOT/PSS (CLEVIOS ${ }^{\mathrm{TM}}$ PHCV4, by H.C.Starck) and a solution of pristine graphene powder has been deposited. A silver nano-particle solution is used for inkjet printing the electrodes onto the PET (PolyEthylene Terephthalate) substrate, through a commercial inkjet printer. The sensing strategy is based on the variation of the electrical conductance of graphene due to gas molecules adsorption. The device responsivity observed in two different operating conditions $\left(50{ }^{\circ} \mathrm{C}\right.$ and $60{ }^{\circ} \mathrm{C}$ ), is $4.0 \mu \Omega / \Omega / \mathrm{ppm}$ and $4.7 \mu \Omega / \Omega / \mathrm{ppm}$. The corresponding values of the resolution are $400 \mathrm{ppm}$ and $420 \mathrm{ppm}$. Main advantages of the developed sensor consist in the cost-effective fabrication techniques and the device flexibility, which are strategic for applications requiring disposable and shapeable devices to be installed into irregular surfaces.
\end{abstract}

Keywords: $\mathrm{CO}_{2}$ monitoring; inkjet printing; gas sensor; PEDOT/PSS; graphene; interdigited electrodes; flexible substrate

\section{Introduction}

Technologies for gas sensors are rapidly developing due to the increasing demand for devices with characteristics compliant to a wide set of applications involving the gas monitoring challenge [1-4]. In particular, carbon dioxide $\left(\mathrm{CO}_{2}\right)$ measurement is a real need for several application contexts including environmental and agriculture monitoring. The monitoring of $\mathrm{CO}_{2}$ levels is strategic for air quality assessment in indoor environments, such as schools, offices and public buildings, especially to control ventilation conditions. Indoor environments, after few minutes of a regular population, show high level of carbon dioxide, especially if these areas are subject to restricted ventilation.

The main subject addressed by this paper concerns the realization of a low cost $\mathrm{CO}_{2}$ sensor by rapid prototyping techniques and the use of conductive inks, polymers and graphene. The latter are interesting for their functional properties as well as for their sensing properties.

One of the most promising conductive polymers is PEDOT-PSS, poly(3,4-ethylenedioxythiophene)poly(styrenesulfonate), which is mechanically flexible, transparent and soluble in water [5,6]. PEDOT/PSS can be used as host and guest material in hybrid systems to improve the mechanical strength and electrical conductivity. In particular, coupling carbon-based materials (e.g., carbon nanotubes 
and graphene) with PEDOT/PSS can result in interesting conductive composites, through surface modification and stabilizing techniques [7]. Graphene is an excellent carbon-based nanomaterial with interesting electrical and optical properties, high transparency, good conductivity and stability, which are sustained by the two-dimensional extended honeycomb network of $s p^{2}$ hybridized carbon atoms [8-10].

Examples of graphene-based $\mathrm{CO}_{2}$ gas sensors are available in the literature [11-13], such as room temperature graphene sheet device, reduced graphene oxide based sensors and hydrogen plasma treated devices [13].

The following notes draw advantages and main features of techniques for the rapid prototyping of electronic devices including sensors. In particular, printed electronics is becoming very interesting due to its intrinsic low cost and the wide availability of different kinds of substrates and materials [14]. Among printing techniques, screen printing is a very low cost mask based technology which produces waste of materials, while inkjet is a direct printing contactless technique characterized by a high resolution, in the order of the tens of micrometers $[15,16]$. Examples of materials compatible with inkjet printing technology are polymers, such as PEDOT-PSS and PANI (Polyaniline), and conductive silver inks.

Microstructures [17], glucose sensors on carbon [18], RFID device [19-21] and paper based humidity sensors [22] are just few examples of devices realized by high cost inkjet printing systems. The use of polymers on conductive electrodes is a common approach for the development of inkjet printed sensors [23].

The use of low cost inkjet printing equipment has been recently introduced as a valuable solution to develop simple devices, exploiting metal inks and a restricted variety of polymers, especially for proof-of-concept tasks [24-28]. Mixed solutions, exploiting screen printing and inkjet technologies, are also available in the literature [29-31].

Concerning printed $\mathrm{CO}_{2}$ gas sensors, an example of a screen printed device is presented in [32], while a first attempt to develop a $\mathrm{CO}_{2}$ sensor based on a polymeric (graphene-based) sensitive layer deposited on inkjet printed electrodes is given in [33].

In this paper the realization and the characterization of a $\mathrm{CO}_{2}$ gas sensor developed by rapid prototyping techniques is presented. The device is based on a combined sensing structure which uses two different polymers PEDOT/PSS and graphene [33]. The main advantage of the proposed solution is the reliable resistive readout strategy, based on the unique sensing feature of the graphene layer and the resistive background given by the PEDOT/PSS.

The adopted low cost printing technologies, as well as the easy inks preparation process, increase the interest in the investigated solution especially for application contexts requiring disposable devices. Moreover, the use of a flexible substrate is valuable to tackle with applications requiring the use of shapeable sensors.

The main novelty introduced by this work is represented by the low operating temperature of the labscale prototype developed by using a cheap inkjet printing technology, as respect to other solutions already available in the literature [12].

\section{The Developed Sensor and the Experimental Set-Up}

\subsection{Description of the Device Structure and Material Properties}

A real view of the inkjet printed gas sensor is shown in Figure 1a. As schematized in Figure 1b, the device uses a flexible PolyEthyleneTerephthalate (PET) substrate for low temperature operation, Novele ${ }^{\mathrm{TM}}$ IJ-220 Printed Electronics Substrate, with a thickness of $140 \mu \mathrm{m}$. InterDigiTed (IDT) electrodes have been printed onto the substrate by using a cheap EPSON WF2010 piezo inkjet printer with a drop resolution of $3 \mathrm{pl}$ and a metal ink adopted for the realization of conductive patterns. The adopted ink is the silver nanoparticle solution Metalon ${ }^{\circledR}$ JS-015 by NovaCentrix (Austin, TX, USA), which is compatible with room temperature printing processes offered by low cost inkjet printers and the 
selected substrate $[23,24]$. To this aim, a compatible cartridge is fill with the silver ink. For a correct operation of the printer and in order to avoid occlusion problems, the piezo print head is preventively cleaned by a series of cleaning cycles using the Metalon Acqueous Vehicle cleaning liquid after every printing session.

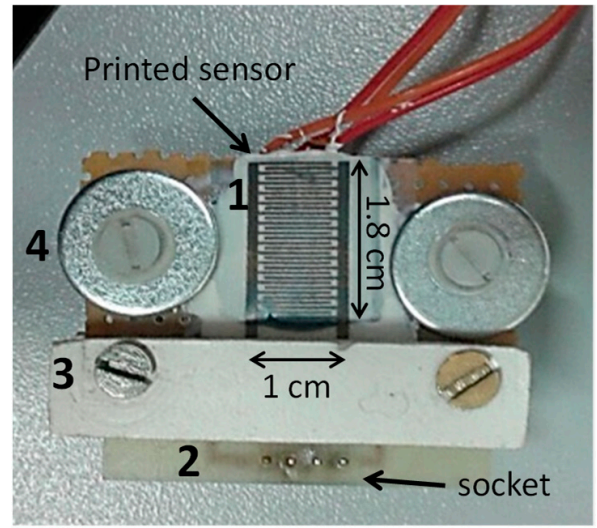

(a)

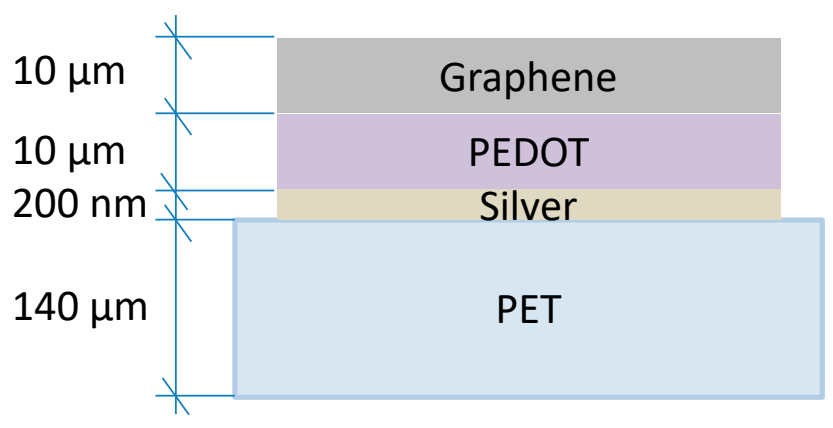

(b)

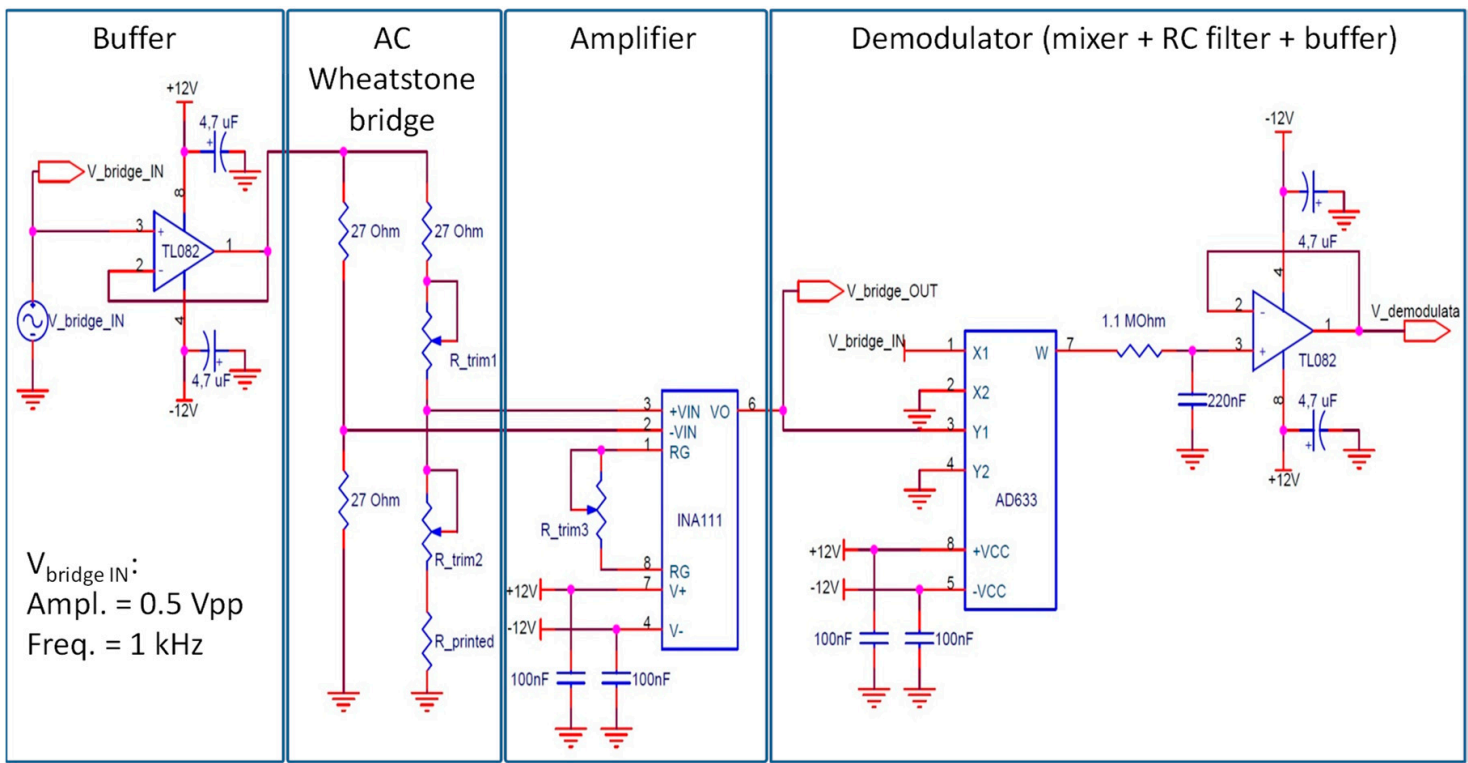

(c)

Figure 1. (a) The real view of the sensor. The sensor dimensions are: $1.8 \mathrm{~cm}$ by $1 \mathrm{~cm}$, with a thickness of about $140 \mu \mathrm{m}$. The IDT fingers (1) have a width of $200 \mu \mathrm{m}$, a length of $6 \mathrm{~mm}$, a thickness of $200 \mathrm{~nm}$ and a track spacing of $350 \mu \mathrm{m}$. A customized socket was used to convey signals to the conditioning electronics (2) and blocked by screws (3). Washers and screws (4) have been also used to fix the sensor to the experimental setup; (b) the sensor structure (not in scale) and (c) the electronics adopted for conditioning the $\mathrm{CO}_{2}$ printed sensor.

A morphologic analysis of the Metalon ${ }^{\circledR J}$ S-015 inkjet printed electrodes, performed by electron microscopy (SEM), has demonstrated the film uniformity, as reported in [24].

The sensing surface deposited over the IDT electrodes consists of two layers, realized by following a different deposition approach as compared the one proposed in [33]. The first layer is made by a commercial PEDOT/PSS, CLEVIOS ${ }^{\mathrm{TM}}$ PHCV4 by H.C.Starck, prepared as the dilution of the starting solution with distilled water $(1: 1, v / v)$. The PEDOT layer has been deposited by a calibrated spreader to reach a thickness of $10 \mu \mathrm{m}$. A heating process bringing the sensor to $80^{\circ} \mathrm{C}$ for 50 min has been applied to produce a conductive dark blue film of PEDOT.

The main reason to use a layer of PEDOT under the sensing layer of graphene is two-fold: 
- to realize a uniform layer over the IDT electrodes guaranteeing continuity of the resistive contact between IDT fingers.

- to realize a layer with a resistance value higher than a pure layer of conductive material (such as the silver ink used to realize IJP IDT electrodes). This allows for making dominant the effect of the resistance variation of the graphene layer, super-imposed to the PEDOT layer, as a consequence of a variation of the concentration of $\mathrm{CO}_{2}$ molecules adsorbed into the sensing layer.

A second layer of the pristine graphene powder, N002-PDR by Angstron Materials, with a concentration of $0.1 \mathrm{mg} / \mathrm{mL}$, mixed with the Triton-X100 nonionic surfactant $(0.4 \mathrm{wt} \%)$, has been deposited over the PEDOT/PSS by a calibrated spreader to reach a thickness of $10 \mu \mathrm{m}$. A sonication process has been applied to the graphene solution to obtain a fine dispersion. Successively, the device has been annealed at $80^{\circ} \mathrm{C}$ for $50 \mathrm{~min}$.

The graphene layer is the one conveying the gas sensing features to the device. The readout strategy mainly exploits the variation of the graphene conductivity as a function of the absorbed amount of gas molecules. In particular, the conductance of the graphene layer increases when the concentration of the $\mathrm{CO}_{2}$ gas increases [12]. The graphene layer acts also as a shield for the PEDOT layer against the effect of exogenous quantities, such as humidity.

The sensor is conditioned by a traditional bridge configuration driven by a sinusoidal signal with an amplitude of $0.5 \mathrm{~V}$ and a frequency of $1.0 \mathrm{kHz}$, followed by gain and demodulation blocks. The schematization of the conditioning electronics is shown in Figure 1c.

The heater, required for the correct operation of the sensor, has been realized through two $10 \Omega$ ceramic power resistors connected in series with a total power of $11 \mathrm{~W}$.

\subsection{Experimental Set up and Procedure}

A heater has been positioned under the sensor substrate to implement the heating process required for the sensor operation and characterization. The substrate temperature is monitored by a Pt100 RTD sensor. The heating process, which is managed by a PID controller and a dedicated LabVIEW tool, allows for increasing the sensor substrate temperature up to $65^{\circ} \mathrm{C}$, which is compliant to the adopted PET substrate.

The experimental set-up developed for the sake of the device characterization is shown in Figure 2. The system consists of an insulated chamber with a controlled gas injection system. The chamber is made of PolyMethylMethAcrylate (PMMA) and has a size of $60 \mathrm{~cm} \times 50 \mathrm{~cm} \times 30 \mathrm{~cm}$ with a total volume of $0.09 \mathrm{~m}^{3}$. The $\mathrm{CO}_{2}$ injection system is equipped with the flowmeter PFM710 by SMC to monitor the $\mathrm{CO}_{2}$ flux, 3 electrically controlled brass valves by Aquili. The CDM4161A sensor has been used to independently measure $\mathrm{CO}_{2}$ concentration during the experiments. The latter is a low-power sensor (300 $\mathrm{mW})$, with an operating range of (400-4200) ppm.

A data management environment has been implemented in LabVIEW, to properly convey signals with a $40 \mathrm{kHz}$ sampling rate and to perform the required signal processing.

During experiments the following gas injection strategy has been adopted: the first action is to reach a steady state regime in the gas injection system; successively $\mathrm{CO}_{2}$ gas is conveyed inside the chamber; when the desired gas concentration has been reached, the new regime is maintained by properly set the input/output valves.

The measurement protocol adopted to operate the printed gas sensor is shown in Figure 3a. The first step consists in conveying clean air inside the chamber up to reach typical environmental $\mathrm{CO}_{2}$ concentrations (around $400 \mathrm{ppm}$ ). Afterwards ten heating cycles are performed (the duration of each heating cycle is $150 \mathrm{~s}$ ), followed by injection of the desired $\mathrm{CO}_{2}$ quantity inside the chamber and successive other 10 heating cycles. For each cycle the sensor is heat up to the desired working temperature. After heating the device, a time interval is waited for reaching a steady state regime. Successively, a new $\mathrm{CO}_{2}$ quantity is injected into the chamber. The procedure ends up when the full scale value of the gas concentration is reached. 


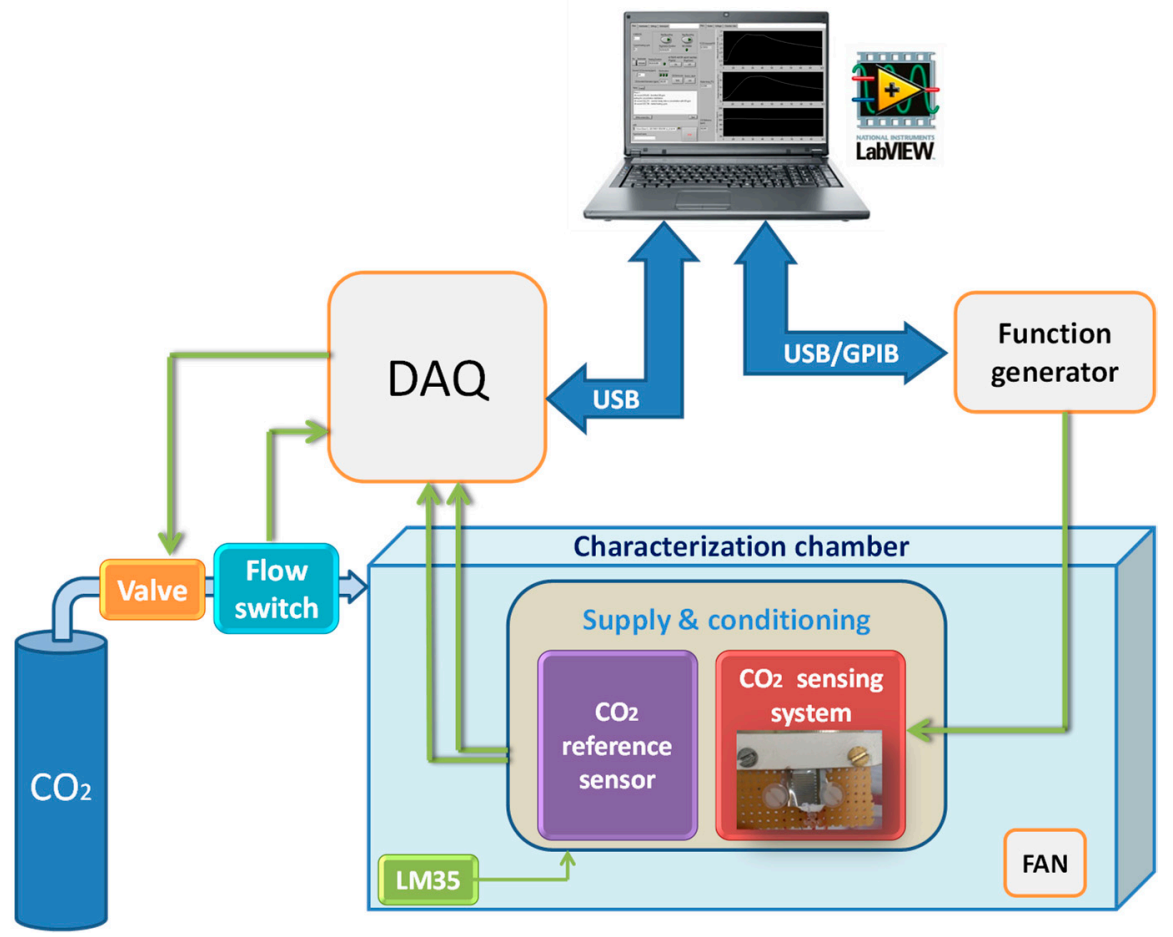

Figure 2. The tool used to assess performances of the sensor developed. The system is composed by an insulated chamber, a reference $\mathrm{CO}_{2}$ sensor and a gas injection system. Sensors data and flow control are managed by a dedicated LabVIEW instrument.

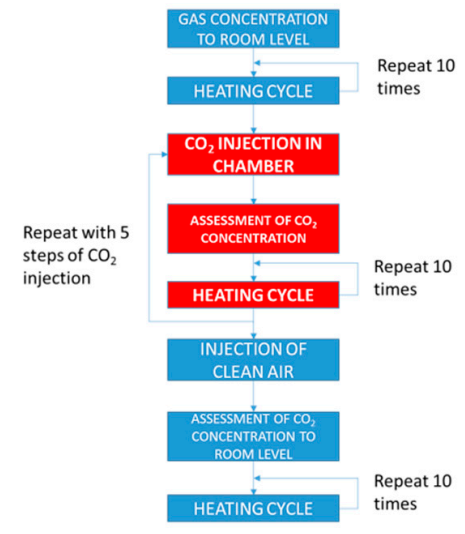

(a)

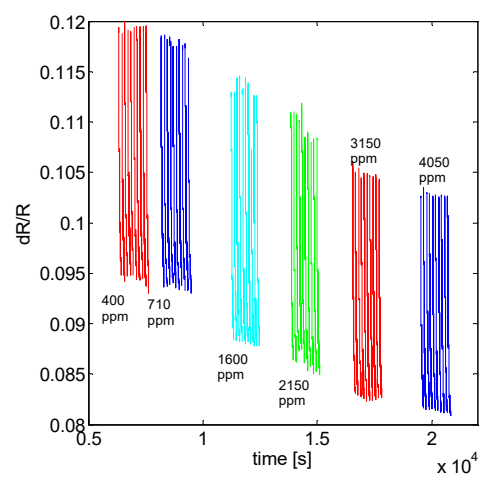

(b)

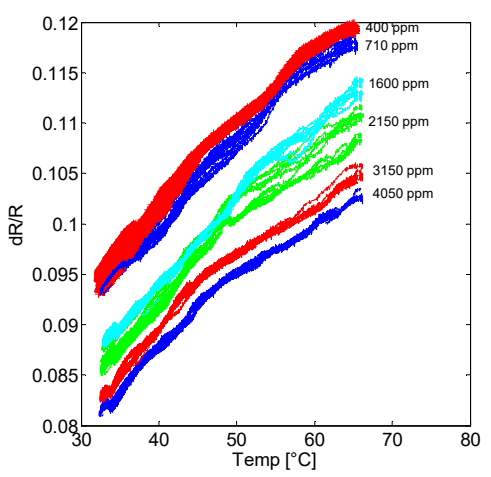

(c)

Figure 3. (a) The flow diagram of the measurement protocol implemented for the lab scale prototype of the Inkjet Printed $\mathrm{CO}_{2}$ sensor; (b) Response of the gas sensor during the heating cycles for different values of the $\mathrm{CO}_{2}$ concentration; (c) The sensor behavior as a function of the heating temperatures and the $\mathrm{CO}_{2}$ concentration.

\section{Experimental Results}

In order to test the sensor behavior against the $\mathrm{CO}_{2}$ concentration and for increasing values of the temperature a characterization survey has been performed. As respect to results presented in [33] a wide range of $\mathrm{CO}_{2}$ concentration has been investigated. In particular, the sensor response for gas concentration up to $4050 \mathrm{ppm}$ was observed, for a working temperature range of $\left(35-65^{\circ} \mathrm{C}\right)$. It must be considered that the investigated range of temperature is compatible with both the flexible substrate and the printed technology adopted to realize the device.

Figure $3 \mathrm{~b}$ shows the sensor output for different values of the gas concentration. These results have been obtained by converting the output voltage provided by the conditioning electronics, shown in 
Figure $1 c$, into the relative variation of the sensor resistance. In order to properly highlight the sensor response as a function of the gas concentration, the relative variation $(d R)$ of the sensor resistance, $R$, with respect to its value in clear air at $20^{\circ} \mathrm{C}, R_{0}$, has been used:

$$
\frac{d R}{R_{0}}=\frac{R-R_{0}}{R_{0}}
$$

For each concentration (see labels in Figure 3b) the response to a number of thermal cycles is reported. As it can be observed, the value of the sensor output changes with the concentration (e.g., see the maximum values of the sensor response). The sensor behavior for different heating temperatures and $\mathrm{CO}_{2}$ concentration is shown in Figure 3c. Obtained results demonstrate the possibility to use this sensor to detect $\mathrm{CO}_{2}$ concentration, once the operating temperature has been fixed.

Examples of the gas sensor response for different values of the operating temperature, $T$, and for increasing values of the $\mathrm{CO}_{2}$ concentration, $C$, are given in Figure 4. As it can be observed, the trend in the sensor response is more convenient in the upper range of the investigated temperatures, especially concerning the sensor linearity.

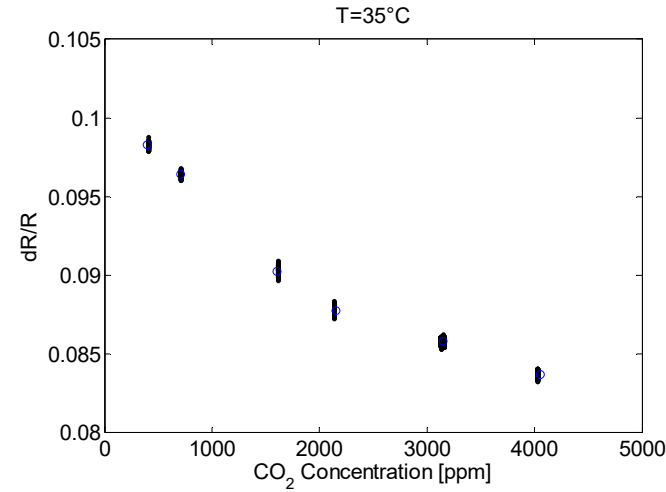

(a)

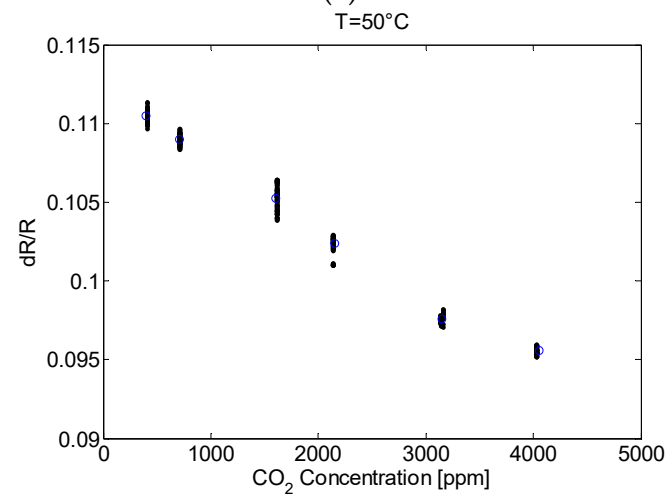

(c)

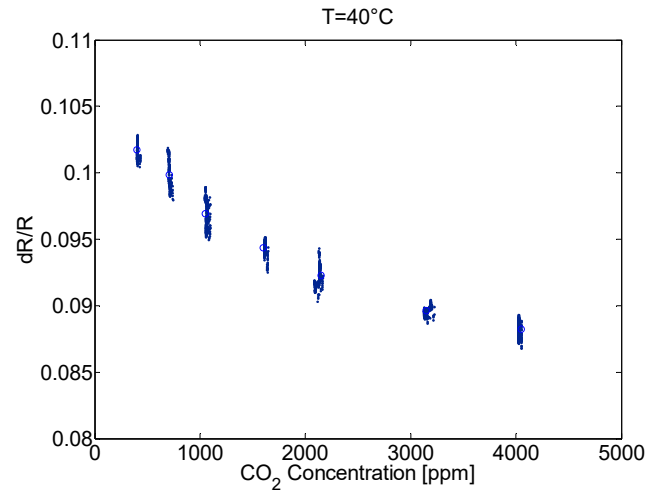

(b)

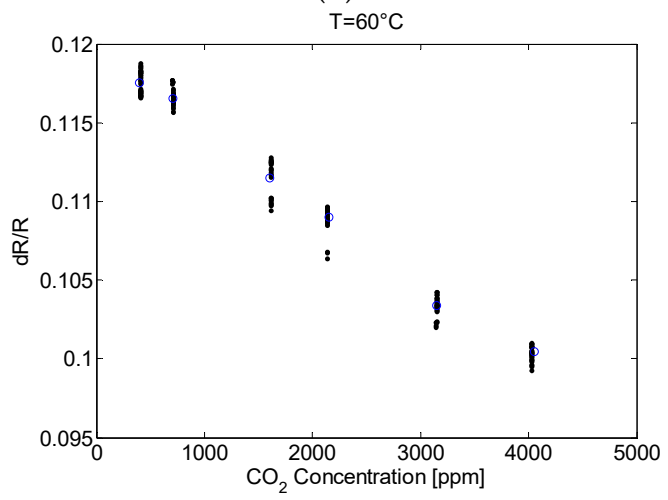

(d)

Figure 4. Printed sensor response in terms of relative variation of the output resistance for increasing values of the $\mathrm{CO}_{2}$ concentration, for different values of the operating temperature: $(\mathbf{a}) 35^{\circ} \mathrm{C},(\mathbf{b}) 40^{\circ} \mathrm{C}$, (c) $50{ }^{\circ} \mathrm{C}$ and (d) $60^{\circ} \mathrm{C}$. Vertical dots state for the dispersion of repeated observations of the sensor response; the circles are the mean values of repeated observations.

Figure 5 shows the sensor response in case of two operating temperatures $\left(50{ }^{\circ} \mathrm{C}, 60{ }^{\circ} \mathrm{C}\right)$. The uncertainty band has been estimated in the $2 \sigma$ level. 


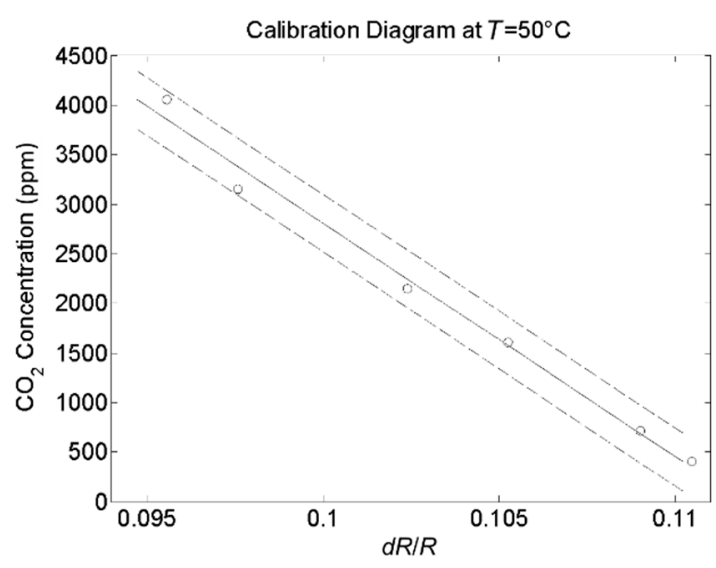

(a)

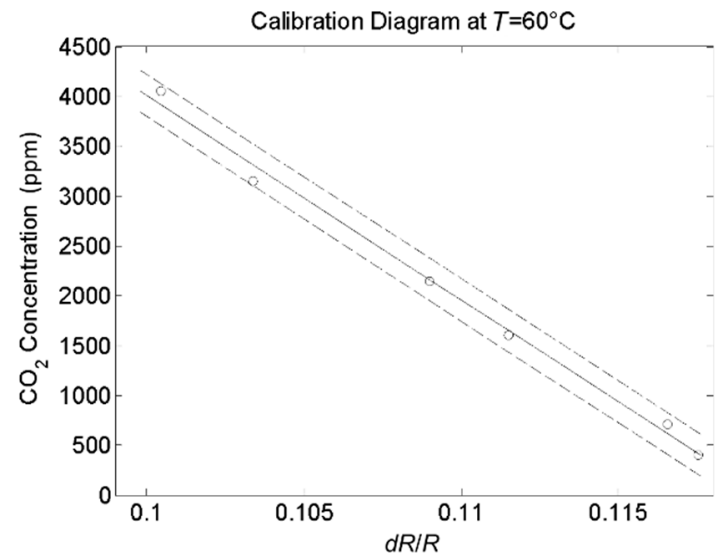

(b)

Figure 5. The calibration diagrams for two operating temperatures: (a) $50{ }^{\circ} \mathrm{C}$ and (b) $60{ }^{\circ} \mathrm{C}$. The uncertainty bands are represented by the dotted lines.

Models adopted to interpolate experimental data are:

$$
\begin{aligned}
& C=-2.3 \times 10^{5} \cdot d R / R+2.6 \times 10^{4}\left(T=50{ }^{\circ} \mathrm{C}\right) \\
& C=-2.0 \times 10^{5} \cdot d R / R+2.4 \times 10^{4}\left(T=60^{\circ} \mathrm{C}\right)
\end{aligned}
$$

The sensor responsivity, $S$, is defined as the ratio between the relative variation of the sensor resistance, $d R / R_{0}$, and the gas concentration $C$ :

$$
S=\frac{\frac{d R}{R_{0}}}{C}\left(\frac{\frac{\Omega}{\Omega}}{\mathrm{ppm}}\right)
$$

The resolution, $\sigma_{C}$, has been estimated as the ratio between the standard deviation of output resistance values, $\sigma_{R}$, observed in case of clean air, and the device responsivity:

$$
\sigma_{C}=\frac{\sigma_{R}}{S}(\mathrm{ppm})
$$

Quantity (5) must be considered as the theoretical limit of the sensor, which could be also affected by the experimental environment. The responsivity and the resolution estimated for the two operating temperatures are given in Table 1.

Table 1. Responsivity and resolution of the $\mathrm{CO}_{2}$ sensor estimated for the two operating temperatures of $50^{\circ} \mathrm{C}$ and $60^{\circ} \mathrm{C}$.

\begin{tabular}{ccc}
\hline $\mathbf{T}\left({ }^{\circ} \mathbf{C}\right)$ & Responsivity $(\boldsymbol{\Omega} / \mathbf{\Omega} / \mathbf{p p m})$ & Resolution $(\mathbf{p p m})$ \\
\hline 50 & $4.01 \times 10^{-6}$ & 400 \\
60 & $4.75 \times 10^{-6}$ & 420 \\
\hline
\end{tabular}

Repeatability tests performed with the device demonstrate a kind of reversibility. By exposing the device to clean air, the output resistivity tends to be restored to its nominal one. Anyway, it has been observed that the device is not fully reversible after a number of cycles during which the sensor is exposed to $\mathrm{CO}_{2}$ concentration. As stated in the conclusion, this is in line with the sensor target to be a disposable low cost device for Early Warning applications.

Several tests have been also carried out to test the reproducibility of the proposed technology. All the devices tested (ten) have shown behaviors similar to the trends described by model (1) and (2), with different offset and slight difference in the responsivity values. The reproducibility is limited 
by the technology adopted to deposit the sensing layer onto the inkjet printed electrodes. Also this behavior is in line with the aim of this work, mainly oriented to the proof-of-concept of the sensing methodology. As outlined in the conclusions, future efforts will be dedicated to fully investigate above aspects.

\section{Conclusions}

In this paper the possibility to realize a $\mathrm{CO}_{2}$ sensor by a rapid prototyping approach, adopting low cost technology and materials, has been demonstrated. The device shows a responsivity of $4.0 \mu \Omega / \Omega / \mathrm{ppm}$ and $4.7 \mu \Omega / \Omega / \mathrm{ppm}$, in case the operating temperatures are $50{ }^{\circ} \mathrm{C}$ and $60{ }^{\circ} \mathrm{C}$, respectively. For the sake of comparison with solutions reported in the state of the art, it can be affirmed that the device responsivity is comparable with other graphene-based $\mathrm{CO}_{2}$ sensors as reported in [34]. The observed responsivity and resolution make the device in line with the target to be a disposable low cost device for Early Warning applications.

The experimental results obtained demonstrate the functionality of the proposed sensing strategy and encourage the development of $\mathrm{CO}_{2}$ sensors by low cost inkjet printing technology.

The sensor cross-sensitivity to other species (interferences) has not been already assessed, especially considering that this work aims at investigating the development of flexible and low cost $\mathrm{CO}_{2}$ sensors to be used in Early Warning systems. In particular, specific environments have been considered as the application scenario, where the candidate gas species are assumed to be known and the exclusive presence of $\mathrm{CO}_{2}$ is supposed (no other gases are supposed to be inflated or generated into the environment under monitoring).

Another activity to be performed is to assess the advantage of using a two layer structure (PEDOT and graphene), also in terms of shielding the resistive layer of PEDOT for the effect of exogenous quantities, such as the humidity. Concerning the effects of the temperature on the sensor output, future works will be dedicated to implement temperature compensation techniques. One possibility to cope with such influences could be the use of a dummy sensor into the Wheatstone bridge adopted to implement the signal conditioning of the sensor. Another solution could rely on a temperature compensation model estimated by heating the device in clean air.

As last, future releases of the device will be designed by including a planar heater to be printed on the opposite side of the PET substrate, as respect to the one hosting the sensing layers.

Author Contributions: Methodology: B.A., G.D.P., A.P., V.M.; Investigations: B.A., S.B., C.G.; Data Curation: S.B., S.G., V.M.; Software: C.L.; Validation: S.G.

Funding: This research has been partially funded by the University of Catania within the project "Piano della ricerca Dipartimentale 2016-2018".

Conflicts of Interest: The authors declare no conflict of interest.

\section{References}

1. Yunusa, Z.; Hamidon, M.N.; Kaiser, A.; Awang, Z. Gas Sensors: A Review. Sens. Transducers 2014, 168, 61-75.

2. Pearton, S.J.; Ren, F. Gallium nitride-based gas, chemical and biomedical sensors. IEEE Instrum. Meas. Mag. 2012, 15, 16-21. [CrossRef]

3. Krutzler, C.; Unger, A.; Marhold, H.; Fricke, T.; Conrad, T.; Schütze, A. Influence of MOS gas-sensor production tolerances on pattern recognition techniques in electronic noses. IEEE Trans. Instrum. Meas. 2012, 61, 276-283. [CrossRef]

4. Saponara, S.; Petri, E.; Fanucci, L.; Terreni, P. Sensor modeling, low-complexity fusion algorithms, and mixed-signal IC prototyping for gas measures in low-emission vehicles. IEEE Trans. Instrum. Meas. 2011, 60, 372-384. [CrossRef]

5. Jonas, F.; Heywang, G. Technical applications for conductive polymers. Electrochim. Acta 1994, 39, $1345-1347$. [CrossRef]

6. Groenendaal, L.B.; Jonas, F.; Freitag, D.; Pielartzik, H.; Reynolds, J.R. Poly (34-ethylenedioxythiophene) and Its Derivatives: Past Present and Future. Adv. Mater. 2000, 12, 481-494. [CrossRef] 
7. Kim, G.H.; Hwang, D.H.; Woo, S.L. Thermoelectric properties of nanocomposite thin films prepared with poly(3,4-ethylenedioxythiophene) poly(styrenesulfonate) and grapheme. Phys. Chem. Chem. Phys. 2012, 14, 3530-3536. [CrossRef]

8. Hill, E.W.; Vijayaragahvan, A.; Novoselov, K. Graphene Sensors. IEEE Sens. J. 2011, 11, 3161-3170. [CrossRef]

9. Fowler, J.D.; Allen, M.J.; Tung, V.C.; Yang, Y.; Kaner, R.B.; Weiller, B.H. Practical chemical sensors from chemically derived graphene. ACS Nano 2009, 3, 301-306. [CrossRef]

10. Dua, V.; Surwade, S.P.; Ammu, S.; Agnihotra, S.R.; Jain, S.; Roberts, K.E.; Park, S.; Ruoff, R.S.; Manohar, S.K. All-organic vapor sensor using inkjet-printed reduced graphene oxide. Angew. Chem. Int. Ed. 2010, 49, 2154-2157. [CrossRef]

11. Novikov, S.; Satrapinski, A.; Lebedeva, N.; Iisakka, I. Sensitivity optimization of epitaxial graphene-based gas sensors. IEEE Trans. Instrum. Meas. 2013, 62, 1859-1864. [CrossRef]

12. Yoon, H.J.; Jun, D.H.; Yang, J.H.; Zhou, Z.; Yang, S.S.; Cheng, M.M.-C. Carbon dioxide gas sensor using a graphene sheet. Sens. Actuators B Chem. 2011, 157, 310-313. [CrossRef]

13. Hafiz, S.M.; Ritikos, R.; Whitcher, T.J.; Razib, N.M.; Bien, D.C.S.; Chanlek, N.; Nakajima, H.; Saisopa, T.; Songsiriritthigul, P.; Huang, N.M.; et al. A practical carbon dioxide gas sensor using room-temperature hydrogen plasma reduced graphene oxide. Sens. Actuators B Chem. 2014, 193, 692-700. [CrossRef]

14. Mäntysalo, M.; Pekkanen, V.; Kaija, K.; Niittynen, J.; Koskinen, S.; Halonen, E.; Mansikkamäki, P.; Hämeenoja, O. Capability of Inkjet Technology in Electronics Manufacturing. In Proceedings of the Electronic Components and Technology Conference, San Diego, CA, USA, 26-29 May 2009.

15. Dimatix Material Printer DMP-2850. Available online: www.fujifilmusa.com/shared/bin/dimatix materials_printer_dmp-2850.pdf (accessed on 10 February 2019).

16. Functional Polymer/Printed Electronics. Available online: www.microdrop.de/functional-polymer-printedelectronics.html (accessed on 10 February 2019).

17. Al-Chami, H.; Cretu, E. Inkjet printing of microsensors. In Proceedings of the IEEE 15th International Mixed-Signals, Sensors, and Systems Test Workshop, Scottsdale, AZ, USA, 10-12 June 2009.

18. Wang, T.; Cook, C.; Derby, B. Fabrication of a Glucose Biosensor by Piezoelectric Inkjet Printing. In Proceedings of the Third International Conference on Sensor Technologies and Applications, Athens, Greece, 18-23 June 2009.

19. Shao, B.; Chen, Q.; Amin, Y.; Hllstedt, J.; Liu, R.; Tenhunen, H.; Zheng, L. Process-dependence of inkjet printed folded dipole antenna for $2.45 \mathrm{GHz}$ RFID tags. In Proceedings of the 3rd European Conference on Antennas and Propagation, Berlin, Germany, 23-27 March 2009.

20. Zheng, L.; Rodriguez, S.; Shao, B. Design and implementation of a fully reconfigurable chipless RFID tag using Inkjet printing technology. In Proceedings of the IEEE International Symposium on Circuits and Systems, Seattle, WA, USA, 18-21 May 2008.

21. Amin, Y.; Prokkola, S.; Botao, S.; Hallstedt, J.; Tenhunen, H.; Zheng, L. Inkjet printed paper based quadrate bowtie antennas for UHF RFID tags. In Proceedings of the 11th International Conference on Advanced Communication Technology, Phoenix Park, Korea, 15-18 February 2009.

22. Andersson, H.; Manuilskiy, A.; Unander, T.; Lidenmark, C.; Forsberg, S.; Nilsson, H.-E. Inkjet printed silver nanoparticle humidity sensorwith memory effect on paper. IEEE Sens. J. 2012, 12-16, 1901-1905. [CrossRef]

23. Andò, B.; Baglio, S. Inkjet-Printed Sensors: A Useful Approach for Low Cost, Rapid Prototyping. IEEE Instrum. Meas. Mag. 2011, 14, 36-40. [CrossRef]

24. Andò, B.; Baglio, S. All-Inkjet Printed Strain Sensors. IEEE Sens. J. 2013, 13, 4874-4879. [CrossRef]

25. Andò, B.; Baglio, S.; Baù, M.; Bulsara, A.R.; Ferrari, V.; Ferrari, M.; L'Episcopo, G. A Nonlinear Energy Harvester by Direct Printing Technology. Procedia Eng. 2012, 47, 933-936. [CrossRef]

26. Andò, B.; Baglio, S.; Bulsara, A.R.; Marletta, V.; Ferrari, V.; Ferrari, M. A Low-Cost Snap-Through Buckling Inkjet Printed Device for Vibrational Energy Harvesting. IEEE Sens. J. 2015, 15, 3209-3220. [CrossRef]

27. Andò, B.; Baglio, S.; Lombardo, C.O.; Marletta, V.; Pistorio, A. A Low-Cost Accelerometer Developed by Inkjet Printing Technology. IEEE Trans. Instrum. Meas. 2016, 65, 1242-1248. [CrossRef]

28. Andò, B.; Baglio, S.; Bulsara, A.R.; Emery, T.; Marletta, V.; Pistorio, A. Low-Cost Inkjet Printing Technology for the Rapid Prototyping of Transducers. Sensors 2017, 17, 748. [CrossRef] 
29. Srichan, C.; Saikrajang, T.; Lomas, T.; Jomphoak, A.; Maturos, T.; Phokaratkul, D.; Kerdcharoen, T.; Tuantranont, A. Inkjet printing PEDOT:PSS using desktop inkjet printer. In Proceedings of the 6th International Conference on Electrical Engineering/Electronics, Computer, Telecommunications and Information Technology, Pattaya, Thailand, 6-9 May 2009.

30. Liu, Y.; Cui, T.; Varahramyan, K. All-polymer capacitor fabricated with inkjet printing technique. Solid State Electron. 2003, 47, 1543-1548. [CrossRef]

31. Fuller, S.B.; Wilhelm, E.J.; Jacobson, J.M. Ink-jet Printed Nanoparticle Microelectromechanical Systems. J. Microelectromech. Syst. 2002, 11, 54-60. [CrossRef]

32. Waghuley, S.A.; Yenorkar, S.M.; Yawale, S.S.; Yawale, S.P. $\mathrm{SnO}_{2} / \mathrm{PPy}$ Screen-Printed Multilayer $\mathrm{CO}_{2} \mathrm{Gas}$ Sensor. Sens. Transducers J. 2007, 79, 1180-1185.

33. Andò, B.; Baglio, S.; di Pasquale, G.; Pollicino, A.; D’Agata, S.; Gugliuzzo, C.; Lombardo, C.; Re, G. An Inkjet Printed $\mathrm{CO}_{2}$ Gas Sensor. Procedia Eng. 2015, 120, 628-631. [CrossRef]

34. Smith, A.D.; Elgammal, K.; Fan, X.; Lemme, M.C.; Delin, A.; Råsander, M.; Bergqvist, L.; Schröder, S.; Fischer, A.C.; Niklaus, F.; et al. Graphene-based $\mathrm{CO}_{2}$ sensing and its cross-sensitivity with humidity. RSC Adv. 2017, 7, 22329-22339. [CrossRef]

(C) 2019 by the authors. Licensee MDPI, Basel, Switzerland. This article is an open access article distributed under the terms and conditions of the Creative Commons Attribution (CC BY) license (http:/ / creativecommons.org/licenses/by/4.0/). 